Conclusions: CCR10 +CD8+T cells have regulatory properties and differentiate Pso from PsA. Future studies are needed to uncover if aberrances in regulatory, cutaneous CD8 + T cells precede the transition to joint disease.

Disclosure of Interest: None declared

DOI: 10.1136/annrheumdis-2018-eular.5237

\section{AB0143 IMPLICATION OF OSTEONECTIN ON CARDIOVASCULAR RISK IN AXIAL SPONDYLOARTHRITIS: A SEROLOGICAL AND GENETIC STUDY}

$\underline{\text { F. Genre }}^{1}$, J. Rueda-Gotor ${ }^{1}$, S. Remuzgo-Martínez ${ }^{1}$, J. Irure-Ventura ${ }^{2}$,

A. Corrales ${ }^{1}$, V. Mijares ${ }^{1}$, V. Portilla ${ }^{1}$, R. Blanco ${ }^{1}$, L. Rodríguez-Rodríguez ${ }^{3}$, J. L. Hernández ${ }^{4}$, J. Llorca ${ }^{5}$, J.G. Ocejo-Vinyals ${ }^{2}$, R. López-Mejías ${ }^{1}$, M.Á. GonzálezGay ${ }^{1} .{ }^{1}$ Epidemiology, Genetics and Atherosclerosis Research Group on Systemic Inflammatory Diseases, IDIVAL; ${ }^{2}$ Immunology Division, Hosp. Univ. M. de Valdecilla, Santander, ${ }^{3}$ Rheumatology Dept, Inst. de Inv. Sanitaria del Hosp. Clín. San Carlos (IDISSC), Hosp. Clín. San Carlos, Madrid; ${ }^{4}$ Bone Metabolism Unit, Dept. of Internal Medicine, Hosp. Univ. M. de Valdecilla, IDIVAL, Univ. of Cantabria, Reticef, ${ }^{5}$ Dept. of Epidemiology and Computational Biology, School of Medicine, Univ. of Cantabria, and CIBER Epidemiología y Salud Pública (CIBERESP), IDIVAL, Santander, Spain

Background: Cardiovascular (CV) disease and atherosclerosis are common causes of morbidity in axial spondyloarthritis (axSpA), ${ }^{1}$ a disease characterised by changes in the osteoproliferative process. A dysregulation in the molecules involved in bone remodelling could also affect the atherosclerotic process, since both processes are linked. ${ }^{23}$ Osteonectin (ON), a key molecule in bone homeostasis, ${ }^{4}$ was associated to obesity, insulin resistance and diabetes. ${ }^{5}$

Objectives: Since the exact role of $\mathrm{ON}$ on $\mathrm{CV}$ risk in axSpA has not been elucidated yet, we evaluated its role in the development of subclinical atherosclerosis and its association with CV risk factors in axSpA patients at the serological and genetic level.

Methods: 171 axSpA patients fulfilling the classification criteria for $\operatorname{axSpA}{ }^{6,7}$ and 84 controls were included in this study. Serum ON levels were measured by multiplex assays. Carotid ultrasound was performed to evaluate the presence of markers of subclinical atherosclerosis. Five $O N$ polymorphisms (rs1054204 [G/C], rs11950384 [G/A], rs13182103 [A/G], rs11745387 [G/A] and rs4958487 [A/G]) were selected by tagging and genotyped using TaqMan assays.

Results: No difference was observed in ON levels between axSpA and controls. Serum ON and CRP levels at study positively correlated in axSpA $(p=0.008)$. Higher ON levels were observed in men, smokers and patients with an atherogenic index indicative of dyslipidemia $(p=0.008,0.01$ and 0.001 , respectively). No association was found between $\mathrm{ON}$ and subclinical atherosclerosis in axSpA. Interestingly, we disclosed that the presence of the A allele of rs13182103 and rs11950384 ON polymorphisms led to lower ON serum levels in axSpA $(p<0.05)$. Furthermore, the presence of the A allele of rs13182103 was linked to a later diagnosis of axSpA when compared to those patients bearing the $G$ allele ( $p=0.002$ ).

Conclusions: Our results show that $\mathrm{ON}$ is linked to inflammation and CV risk factors in axSpA and suggest that the A allele of rs13182103 and rs 11950384 ON polymorphisms may have a protective effect in axSpA, leading to reduced ON serum levels and later diagnosis of the disease. These data support an implication of $\mathrm{ON}$ in the development and progression of atherosclerotic disease in axSpA.

\section{REFERENCES:}

[1] Joint Bone Spine 2014;81(1):57-63

[2] Clin Chim Acta 2015;438:401-14.

[3] Arterioscler Thromb Vasc Biol 2001;21(12):1998-2003.

[4] J Bone Miner Res 2015;30(4):723-32.

[5] Int J Clin Exp Med 2015;8(10):19290-6.

[6] Ann Rheum Dis 2009;68:777-83.

[7] Arthritis Rheum 1984;27:361-8.

Acknowledgements: FG is a recipient of a Sara Borrell post-doctoral fellowship from Instituto de Salud Carlos III (ISCIII, Spain), co-funded by European Social Fund (ESF,CD15/00095). SR-M is supported by funds of RETICS Program (RD16/0012/0009,ISCIII,co-funded by European Regional Development Fund, ERDF). RL-M is a recipient of a Miguel Servet type I fellowship from ISCIII, cofunded by ESF(CP16/00033). VM is supported by funds of a Miguel Servet type I (CP16/00033)(ISCIII, co-funded by ERDF).
Disclosure of Interest: None declared

DOI: 10.1136/annrheumdis-2018-eular.5186

\begin{tabular}{|l|l}
\hline AB0144 & NMR BASED SERUM AND SYNOVIAL FLUID \\
METABOLOMICS REVEAL SIMILAR METABOLOMIC \\
PROFILE IN PATIENTS WITH REACTIVE ARTHRITIS \\
AND UNDIFFERENTIATED SPONDYLOARTHROPATHY
\end{tabular}

R. Misra $^{1}$, D. Dubey ${ }^{2}$, S. Ahmed ${ }^{3}$, S. Chaurasia ${ }^{1}$, S. Chaudhary ${ }^{1}$, A. Guleria ${ }^{2}$, D. Kumar? ${ }^{2}{ }^{1}$ Clinical Immunology, Sanjay Gandhi Post Graduate Institute of Medical Sciences; ${ }^{2}$ Centre for Biomedical Research; ${ }^{3}$ Sanjay Gandhi Post Graduate Institute of Medical Sciences, Lucknow, India

Background: Reactive arthritis ( $\operatorname{ReA})$ and undifferentiated spondyloarthropathy (USpA) have similar clinical picture, the former is prededed by mucosal infections and the latter do not meet criteria of well defined entity of seronegative spondyloarthropathy (SSA) We have shown that both ReA and uSpA have similar synovial fludid $T$ cell response to salmonella antigens and cytokine profile.

Objectives: To investigate if the metabolic profiles of $\mathrm{ReA}$ in sera and synovial fluid are different from those of USpA

Methods: Standard defnitions were used to classify patients as $\operatorname{ReA}^{2}$ and $u S p A^{3}$ Metabolic profiles in sera and synovial fluid samples were measured using $1 \mathrm{D}^{1} \mathrm{H}$ NMR spectroscopy and analysed using CHENOMX@ software. The quantitative profiles between the groups were compared using Partial Least Square-Discriminatory Analysis (PLS-DA) and $\mathrm{Q}^{2}$ parameter was used to assess the metabolic differences between the groups.

Results: The study involved $19 \mathrm{ReA}$ and $13 \mathrm{USpA}$ patients with median age 26 (21-33.75) years. Of 32 patients: 7 (22\%) were females, three(12\%) had monophasic illness, $16(64 \%)$ polyphasic, and six(24\%) persistent arthritis (follow-up data was not available for 7). $27 \%$ had monoarticular, $59 \%$ oligoarticular and $14 \%$ polyarticular involvement. Six had inflammatory backpain, three had oral ulcers, one dactylitis, but none had mucocutaneous manifestations. Two had asymptomatic sacroiliitis on radiographs.

Compared to normal controls ( $n=18$, median age $=29$ years, male:female $=17: 1$ ), the sera of ReA/USpA patients were characterised by elevated levels of malonate, mannose, $\mathrm{N}$-nitrosodimethylamine, and pyruvate, whereas 3-hydroxyisovalerate was decreased significantly (T-test $p$-value $<0.001$ ). PLS-DA analysis between sera and synovial fluid samples showed clear demarcation with higher pyruvate and acetoacetate and lower aspartate, methanol, ethanol, and methylsuccinate in synovial fluid samples compared to sera (t-test $p<0.01$ ). The PLS-DA analysis of sera showed little difference between ReA and USpA (figure 1) while that of synovial fluid showed $Q^{2}<0$ for all models. Further no significant metabolic differences in sera/synovial fluid were found between HLA-B27 positive and negative groups $\left(Q^{2}<0\right.$ in all models).
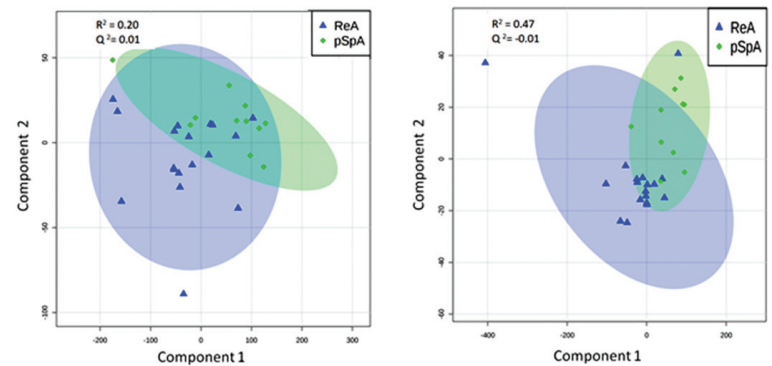

Abstract AB0144 - Figure 1. (a) PLSDA of sera of HLA B27 positive versus negative patients (b) PLSDA of synovial fluid of HLA B27 positive versus negative patients

Conclusions: ReA and USpA have indistinguishable metabolomics profiles in sera and synovial fluid reflecting similar metabolo-inflammatory pathways involved.

\section{REFERENCES}

[1] Chaurasia S, Shasany AK, Aggarwal A, Misra R. 2016 Aug;185(2):210-8.

[2] Braun J, Kingsley G, et sl. Journal of Rheumatology 2000;27:2185-92.

[3] Sieper J, Rudwaleit M, et al. Ann Rheum Dis. 2009 Jun;68(Suppl 2):ii144

Disclosure of Interest: None declared

DOI: 10.1136/annrheumdis-2018-eular.6257 